\title{
The Median Effective Dose of Oxytocin Needed to Prevent Uterine Atony During Cesarean Delivery in Elderly Parturients
}

This article was published in the following Dove Press journal: Drug Design, Development and Therapy

\author{
Chang $\mathrm{Na} \mathrm{Wei}{ }^{1,2, *}$ \\ Jia Li Deng ${ }^{1,2, *}$ \\ Jin Hua Dong ${ }^{3}$ \\ Ze Peng Ping ${ }^{3}$ \\ Xin Zhong Chen ${ }^{1,2}$
}

'Department of Anesthesia, Women's Hospital, Zhejiang University School of Medicine, Hangzhou 3I0006, People's Republic of China; ${ }^{2}$ Department of Anesthesia, Jiaxing University Affiliated Women and Children Hospital, Jiaxing 3/4000, People's Republic of China; ${ }^{3}$ Department of Obstetrics, Jiaxing University Affiliated Women and Children Hospital, Jiaxing 314000 ,

People's Republic of China

*These authors contributed equally to this work
Correspondence: Xin Zhong Chen Department of Anesthesia, Women's Hospital, Zhejiang University School of Medicine, Xueshi Road I, Hangzhou 310006 ,

People's Republic of China

Tel +86 13575738058

Email chenxinz@zju.edu.cn
Purpose: Oxytocin is the first-line agent to prevent and treat uterine atony during cesarean delivery (CD). We compared the effective dose in $50 \%$ of the parturients $\left(E_{50}\right)$ of a prophylactic oxytocin bolus during $\mathrm{CD}$ in young ( $<35$ years) and old parturients $(\geq 35$ years) using Dixon's up-and-down method.

Patients and Methods: Twenty-eight young parturients (young group) and 25 old parturients (old group) undergoing CD under combined spinal-epidural anesthesia were enrolled. The initial oxytocin bolus was $0.5 \mathrm{IU}$, with increments or decrements of $0.25 \mathrm{IU}$. Maternal adverse effects, requirement for additional uterotonic agents, and estimated blood loss were recorded.

Results: The $\mathrm{ED}_{50}$ for oxytocin in the old group was higher than that in the young group (1.41 IU; 95\% confidence interval, 0.63-2.19) vs 0.66 IU $(0.04-1.29), P<0.001)$. The total oxytocin dose in the old group was higher than in the young group $(5.9 \pm 2.9 \mathrm{vs} 4.1 \pm 2.1 \mathrm{IU}$, $P=0.01)$. The estimated blood loss in the older group and young group was $401.2 \pm 204.5$ $\mathrm{mL}$ and $289.3 \pm 104.6 \mathrm{~mL}$, respectively $(P=0.01)$. The overall prevalence of adverse effects was higher in the old group than in the young group $(68.0 \%$ vs $21.4 \%, P<0.001)$.

Conclusion: The initial bolus and total requirement of oxytocin for preventing uterine atony were higher in old parturients than in young parturients during CD. Advanced maternal age may necessitate higher doses of oxytocin.

Keywords: maternal age, drug delivery, bolus, postpartum haemorrhage prevention

\section{Introduction}

Over recent decades, the mean maternal age in "developed" countries has been increasing gradually. Parturients over the age of 35 years have started to comprise an important proportion of the pregnant population. ${ }^{1,2}$ In China, the government estimated that $60 \%$ of the women who have benefited from the universal two-child policy are older than 35 years. $^{3}$ Older age is associated with a significantly increased risk of intrapartum complications (eg, requirement for cesarean section and postpartum hemorrhage). ${ }^{4-6}$

Smith and colleagues showed that spontaneous contraction of isolated myometrium during human pregnancy ex vivo decreased and exhibited increased multiphasic contractions with advancing maternal age. ${ }^{7}$ Also, myometrial tissue responds less effectively to oxytocin with increasing maternal age in the non-pregnant state. $^{8,9}$ Also, parturients of advanced age are more likely to require oxytocin augmentation for induction of labor. ${ }^{9}$ 
Oxytocin administration immediately after delivery of the fetus during cesarean delivery (CD) is recommended to prevent uterine atony and to treat established postpartum hemorrhage. The intravenous infusion dose of oxytocin after delivery during $\mathrm{CD}$ is controversial, so a universal dose for all cases is not appropriate. ${ }^{10}$

We hypothesized that older parturients would require more oxytocin to achieve an adequate uterine tone (UT) compared with that of their younger counterparts. We wished to investigate the effects of age on sensitivity to oxytocin during $\mathrm{CD}$. We selected 53 patients scheduled for $\mathrm{CD}$ under spinal anesthesia to identify the effective dose in $50 \%$ of the parturients $\left(\mathrm{ED}_{50}\right)$ for oxytocin (using the Dixon up-and-down method (DUaDM ${ }^{11}$ ) for an adequate UT between old ( $\geq 35$ years) and young ( $<35$ years) groups.

\section{Patients and Methods}

\section{Ethical Approval of the Study Protocol}

The present study was conducted in accordance with the principles stated in the Declaration of Helsinki 1964 and its later amendments. The study protocol was approved (2018-81) by the Ethics Committee of Jia Xing University Affiliated Women and Children Hospital (Jia Xing, China) in September 2018. Written informed consent was obtained from all participants. Our study was registered (30 May 2019) before patient enrolment in the Chinese Clinical Trial Registry (ChiCTR1900023469: Principal Investigator: $\mathrm{CN}$ Wei) and was conducted between 30 May and 20 December 2019.

\section{Inclusion Criteria}

The inclusion criteria were healthy parturients 1) with American Society of Anesthesiologists grade II; 2) between 18 and 45 years of age; 3) with a singleton pregnancy; 4) gestational age $\geq 37$ weeks; 5) with a planned elective CD using the Pfannenstiel incision.

\section{Exclusion Criteria}

The exclusion criteria were as follows: 1) significant obstetric disease (including pregnancy-induced hypertension or pre-eclampsia); 2) body mass index $\geq 40 \mathrm{~kg} / \mathrm{m}^{2}$; 3) active labor; 4) ruptured membranes; 5) previous resection of uterine fibroids; 6) known allergy to oxytocin; and 7) risk factors for postpartum hemorrhage (placenta previa, multiple gestations, macrosomia, polyhydramnios, uterine fibroids, history of uterine atony and postpartum bleeding, or bleeding diathesis).

\section{Study Groups}

All parturients were divided into two groups based on age: young group (18-34 years of age) and old group (35-45 years of age). All parturients were treated with secondary $\mathrm{CD}$ and parity was 2 . A history of $\mathrm{CD}$ was the primary indication for elective $\mathrm{CD}$.

\section{$C D$}

Upon arrival in the operating theatre, an intravenous cannula was inserted in the dorsum of a hand. An infusion of Ringer's lactate solution $(500 \mathrm{~mL})$ was started $30 \mathrm{~min}$ before initiation of combined spinal-epidural anesthesia (CSE). Standard monitoring comprised five-lead electrocardiography, non-invasive blood pressure (NIBP) monitoring, heart rate (HR) and pulse oximetry. NIBP and heart rate were recorded every 3 min throughout $\mathrm{CD}$. CSE was undertaken in the L3/4 interspace using the loss-of-resistance method. Spinal anesthesia was induced with $0.5 \%$ hyperbaric bupivacaine $(9-12 \mathrm{mg}$ ) based on abdominal girth and vertebral-column length ${ }^{12}$ to achieve a block height at the T5 dermatome. All parturients received supplemental oxygen via a nasal cannula at $3 \mathrm{~L} / \mathrm{min}$ until delivery of the fetus. Intraoperative fluid management was at the discretion of a very experienced anesthetist who was not involved in the scientific aspects of this study.

"Hypotension" was defined as a systolic blood pressure $<90 \mathrm{mmHg}$ or a decrease $>20 \%$ from baseline, and was treated with phenylephrine $(100 \mu$ g, i.v. $)$. Parturients not responding to phenylephrine were treated with ephedrine (6 mg). "Tachycardia" was defined as HR $\geq 120$ beats/min.

Immediately upon delivery of the fetus, one bolus of oxytocin (Nanjing Xinbai Pharmaceuticals, Nanjing, China) in a scaled syringe was administered (i.v.) over 5 s. The DUaDM was used to determine the oxytocin dose. The initial bolus of oxytocin was $0.5 \mathrm{IU}$ for the first parturient in both groups. The oxytocin dose for the next parturient in the corresponding group was determined by the response of the previous parturient to a higher dose or lower dose of oxytocin. The increment or decrement was set as $0.25 \mathrm{IU}$ for both groups. If the response of the previous parturient to the initial bolus of oxytocin was "adequate", the dose for the next parturient was decreased by $0.25 \mathrm{IU}$. If the response of the previous parturient was "inadequate", the dose for the next parturient was 
increased by $0.25 \mathrm{IU}$. After delivery of the fetus, the obstetrician facilitated spontaneous delivery of the placenta with cord traction, but without uterine massage, after which the uterus was exteriorized. Two-layer sutures were adopted for the uterus. The UT was evaluated by a senior attending obstetrician (blinded to the study protocol) while undertaking CD (such as suture of the uterus, and stopping bleeding). The UT was evaluated 3, 6, and 9 min after oxytocin administration. The obstetrician evaluated the UT subjectively at each time point as "adequate" or "inadequate". If the UT was considered to be adequate at $3 \mathrm{~min}$, then an oxytocin infusion (3 IU oxytocin diluted in $20 \mathrm{~mL}$ of physiologic $(0.9 \%)$ saline) at $3 \mathrm{IU} / \mathrm{h}$ was started. If the UT was considered inadequate $3 \mathrm{~min}$ after administration, then a "rescue" dose of oxytocin (3 IU) was administered within $30 \mathrm{~s}$. If the UT remained inadequate after two rescue doses of oxytocin, an alternative uterotonic agent (methylergonovine maleate $(0.2 \mathrm{mg}$, i. $\mathrm{m}$.); carboprost tromethamine $(0.25 \mathrm{mg}$, i.m. $)$ or misoprostol (800-1000 mg, p.r.)) was administered.

The primary outcomes were an adequate or inadequate UT 3 min after the administration of the first dose of oxytocin, and the total requirement for oxytocin. Secondary outcomes were: total volume of crystalloid infused intravenously; delivery time for the placenta; estimated blood loss (quantified as the sum of blood in the suction canister and weight of blood on surgical sponges and the maternity pad); postoperative hemoglobin level (measured $30 \mathrm{~min}$ after CD completion); requirement for additional uterotonic agents; oxytocin-related adverse effects (hypotension, nausea, vomiting, headache, tachycardia, flushing, and chest pain). The lowest blood pressure during the 15-min interval after administration of the oxytocin bolus was recorded. Demographic characteristics, antepartum hemoglobin level, amniotic fluid volume (estimated by suction), fetal weight, and duration of the surgical procedure were also recorded.

\section{Statistical Analyses}

Data are the mean $\pm \mathrm{SD}$, median (range), or the number of patients. Data were assessed for a normal distribution of variance using normality plots and the KolmogorovSmirnov test. Differences between groups were analyzed using an independent $t$-test or the Mann-Whitney $U$-test as appropriate. Binomial data were obtained using the chisquared test, Yates correction, or Fisher's exact test where appropriate. Statistical analyses were carried out using
SPSS 19.0 (IBM, Armonk, NY, USA). P $<0.05$ was considered significant.

The $\mathrm{ED}_{50}$ of the initial bolus of oxytocin after delivery was determined by calculating the mean of the midpoint of the pair of oxytocin doses in successive parturients in which an inadequate response was followed by an adequate response (crossover) according to the DUaDM. ${ }^{13-15}$

The sample size was considered to be sufficient if six pairs of "crossover" points were obtained as the DUaDM was applied for $\mathrm{ED}_{50}$ evaluation. Simulation studies using the DUaDM suggested that $\geq 20$ patients should be included to obtain stable estimates. ${ }^{11,16}$ Increasing the number of crossovers could improve the $\mathrm{ED}_{50}$ estimate, but the magnitude of the improvement would be small. ${ }^{17}$ We decided to obtain seven crossovers for the present study.

\section{Results}

Fifty-eight parturients were approached, of whom five declined to participate in our study. Fifty-three parturients were included in the final analysis: 28 in the young group and 25 in the old group. Demographic characteristics and CD details are shown in Table 1, which were similar between both groups except for maternal age, which was higher in the old group.

The subsequent response of each dose of oxytocin (adequate or inadequate) determined by the DUaDM is shown in Figure 1. The $\mathrm{ED}_{50}$ of oxytocin using midpoint analyses was higher in the old group compared with that in the young group $(1.41 \mathrm{IU} ; 95 \%$ confidence interval $0.63-$ $2.19)$ vs 0.66 IU $(0.04-1.29), P<0.001)$. The doseresponse curves of oxytocin in the two groups are shown in Figure 2. The total oxytocin requirement was higher in the old group compared with that in the young group (5.9 \pm 2.9 vs $4.1 \pm 2.1 \mathrm{IU}, P=0.01)$.

Secondary outcomes and adverse events are shown in Table 2. The estimated blood loss of the old group and young group was $401.2 \pm 204.5 \mathrm{~mL}$ and $289.3 \pm 104.6 \mathrm{~mL}$, respectively, which was significantly different between the two groups $(P=0.01)$. The overall prevalence of adverse effects was higher in the old group compared with that in the young group $(68.0 \%$ vs $21.4 \%, P<0.001)$. Thirty-two percent of parturients in the old group required supplemental uterotonics compared with $10.7 \%$ in the young group $(P=0.06)$. None of the parturients in the two groups experienced tachycardia. The postoperative hemoglobin level, total volume of crystalloid administered, lowest 
Table I Demographic Characteristics and Details of Cesarean Delivery

\begin{tabular}{|c|c|c|c|}
\hline Variables & $\begin{array}{l}\text { Young } \\
(n=28)\end{array}$ & $\begin{array}{l}\text { Old } \\
(n=25)\end{array}$ & $P$ \\
\hline Age (years) & $29.5 \pm 3.7$ & $37.7 \pm 2.3$ & $<0.001$ \\
\hline Weight (kg) & $68.8 \pm 6.5$ & $71.6 \pm 6.6$ & 0.13 \\
\hline Height (cm) & $160.3 \pm 3.5$ & $159.6 \pm 3.7$ & 0.50 \\
\hline Body mass index $\left(\mathrm{kg} / \mathrm{m}^{2}\right)$ & $26.8 \pm 2.5$ & $27.6 \pm 2.0$ & 0.19 \\
\hline Gestational age (weeks) & $39(38,40)$ & $39(38,40)$ & 0.64 \\
\hline Volume of amniotic fluid $(\mathrm{mL})$ & $595.7 \pm 211.8$ & $606.8 \pm 241.6$ & 0.86 \\
\hline Preoperative hemoglobin (g/L) & $117.7 \pm 10.3$ & $113.2 \pm 8.4$ & 0.22 \\
\hline \multicolumn{4}{|l|}{ Blood pressure at baseline $(\mathrm{mmHg})$} \\
\hline Systolic & $102.3 \pm 7.5$ & $105.0 \pm 8.7$ & 0.21 \\
\hline Diastolic & $51.6 \pm 7.7$ & $54.8 \pm 8.7$ & 0.16 \\
\hline Mean & $71.9 \pm 6.4$ & $74.8 \pm 7.2$ & 0.12 \\
\hline Heart rate at baseline (beat/min) & $89.8 \pm 9.2$ & $86.0 \pm 10.1$ & 0.16 \\
\hline Fetal weight (g) & $3386.4 \pm 333.4$ & $3423.6 \pm 281.1$ & 0.11 \\
\hline Duration of CD (min) & $41.8 \pm 8.3$ & $46.0 \pm 9.8$ & 0.10 \\
\hline
\end{tabular}

Note: Data are the mean \pm standard deviation or median (range).

blood pressure, and the delivery time for the placenta were similar between the two groups.

\section{Discussion}

We discovered that the $\mathrm{ED}_{50}$ of the oxytocin bolus administered to prevent uterine atony during $\mathrm{CD}$ was almost two times greater in old parturients than in young parturients. Besides, the total oxytocin requirement was higher in the old group than in the young group. Our data will help clinicians understand and potentially "tailor" the amount of oxytocin administered to older parturients undergoing $\mathrm{CD}$.

There has been considerable debate over the past decade surrounding the optimal dose and mode of oxytocin administration after delivery of the fetus during CD. ${ }^{10,18-20}$ The most recent consensus statements have suggested a bolus-and-infusion regimen for uterotonic administration for low-risk, elective $\mathrm{CD}$, and $\mathrm{CD}$ in women during labor. A universal dose for all cases is not appropriate, and the optimal dose and mode of oxytocin administration for particular individuals is highly desirable. ${ }^{10}$ We chose to study the $\mathrm{ED}_{50}$ of oxytocin by bolus because 1) this mode of administration, rather than an infusion, is common in China and 2) very low doses are required by infusion after an initial bolus. $^{21}$
Bobrowski et al have performed a retrospective review of antepartum and delivery data of 9556 singleton pregnancies of women aged 20 to 29 or $\geq 35$ years who delivered over 8 years, and found the elderly gravidas had the greatest age-related increases in oxytocin use (1.7times). ${ }^{22}$ Similarly, in the current study, parturients in the old group had a higher initial bolus dose of oxytocin, total oxytocin requirements, and estimated blood loss than those in the young group.

The mechanism of the age-induced increase in oxytocin demand for $\mathrm{CD}$ is incompletely understood. One possible explanation is that increasing maternal age is associated with reduced spontaneous activity of the myometrium and an increased likelihood of multiphasic contractions. ${ }^{7}$ These actions may lead to myometrial tissue responding less effectively to uterotonic agents (eg, oxytocin) with increasing maternal age, and scholars have observed this phenomenon. ${ }^{8,9,23}$ Arrowsmith and colleagues suggested that receptor expression/coupling to $\mathrm{Ca}^{2+}$ entry and contraction may decrease as maternal age advances. ${ }^{8}$ At the molecular level, Patel and colleagues found that expression of oxytocin receptors and connexin43 mRNA was reduced in the myometrium from 8-monthold pregnant mice compared with that in 3-month-old pregnant mice. They documented a significant reduction in the copy number of mitochondrial-DNA in the 


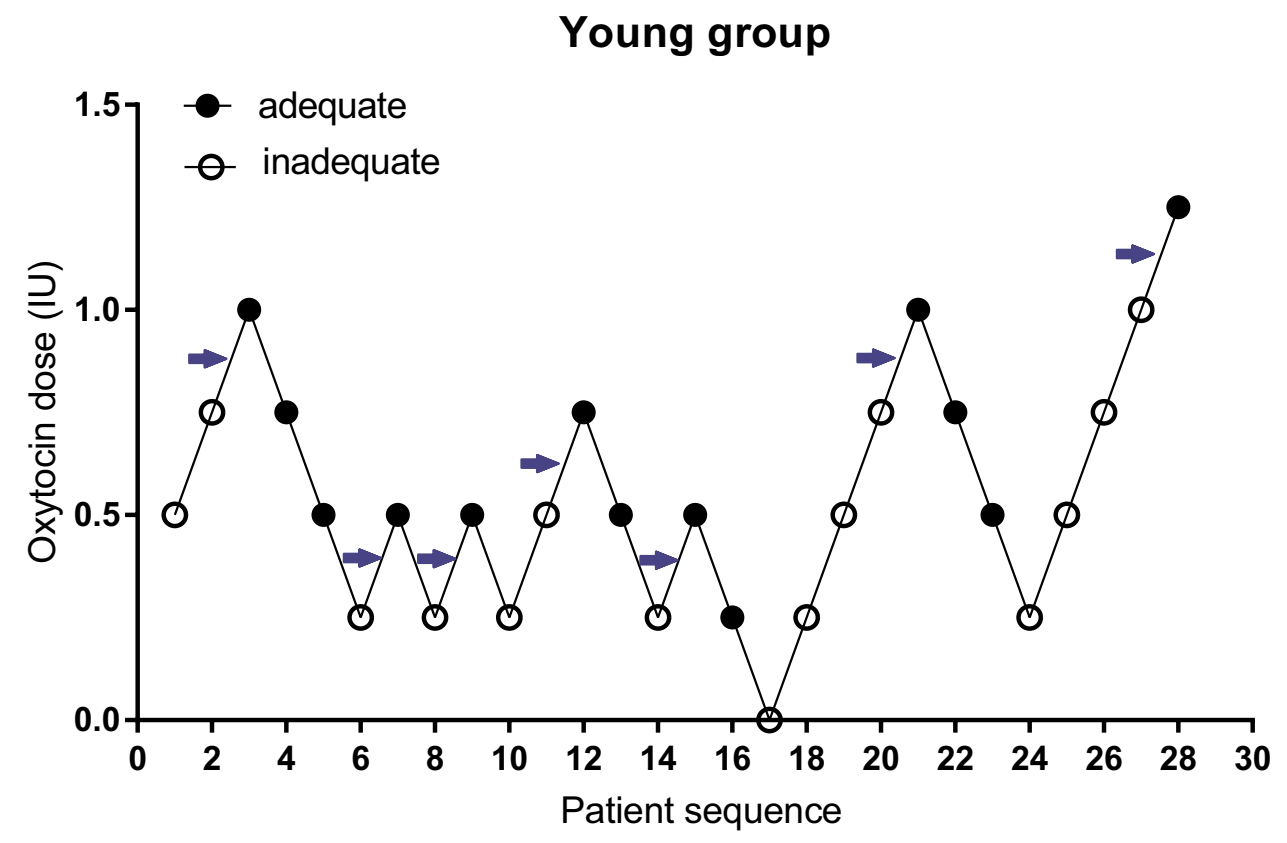

Old group

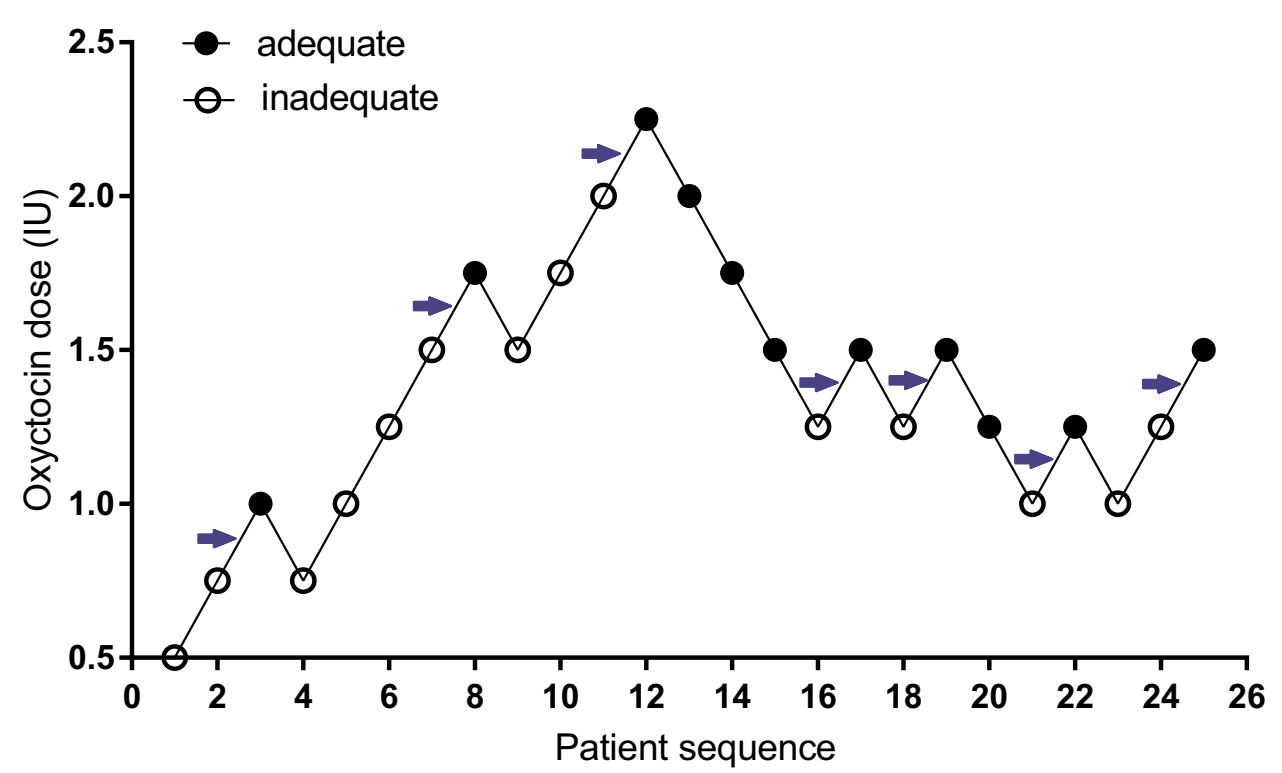

Figure I Dixon's up-and-down sequential allocation response (adequate or inadequate uterine tone 3 min after delivery) in young or old parturients after an initial oxytocin bolus. The initial dose in both groups was $0.5 \mathrm{IU}$, and the incremental change was $0.25 \mathrm{IU}$. The arrow shows seven midpoints of each group crossing from an "inadequate" uterine tone (empty circle) to "adequate" uterine tone (filled circle). The estimated effective dose in $50 \%$ of parturients was $0.66 \mathrm{IU}$ ( $95 \%$ confidence interval, $0.04-\mathrm{I} .29$ ) in the young group and I.4I IU $(0.63-2.19)$ in the old group $(P<0.00 \mathrm{I})$.

myometrium from older mice. This action could contribute to impaired contractile activity via reduction in overall synthesis of adenosine triphosphate or altered regulation of intracellular $\mathrm{Ca}^{2+.24}$ The higher requirement of oxytocin to obtain an adequate UT in older parturients during CD may contribute to a decline in myometrial function.

Oxytocin is associated with adverse events such as hypotension, myocardial ischemia, arrhythmias, nausea, vomiting, chest pain, headache, and flushing. A small dose and slow administration of oxytocin results in fewer adverse effects. $^{25-27}$ Butwick and colleagues ${ }^{28}$ undertook a dose-response study for oxytocin, and found that the prevalence of adverse effects increased with doses $>1$ IU. We also found a significant increase in overall side effects in the old group that received higher doses of oxytocin even though we adopted a slow rate of administration. 


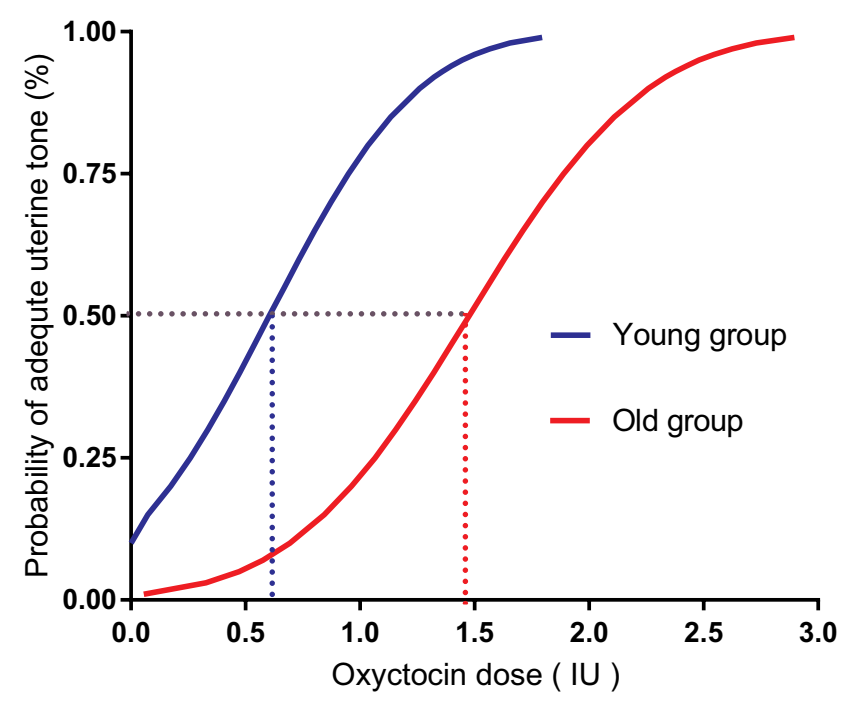

Figure 2 Dose-response curve of the oxytocin bolus needed to obtain an adequate uterine tone plotted from the estimated probabilities of an effective response ( $1 \%-100 \%)$ versus the corresponding oxytocin doses calculated using probit analyses.

Most of the studies investigating the relationship between advanced maternal age and postpartum hemorrhage have been retrospective, and many have not controlled for confounding variables (eg, maternal disorders).
Discrepancies exist in the literature. ${ }^{29,30}$ Several studies on the oxytocin dose for maintaining the UT during elective $\mathrm{CD}$ have been published, ${ }^{28,31,32}$ but none have focused on the effect of age on the oxytocin dose during $\mathrm{CD}$. The present study was a double-blinded, dual-arm, doseresponse study focusing on the effect of age on the oxytocin dose required to prevent uterine atony during $\mathrm{CD}$. Our results suggest that obstetricians and anesthesiologists should consider the age of the parturient as a main factor when deciding the oxytocin dose for preventing uterine atony during $\mathrm{CD}$.

Our study had four main limitations. First, analyses of the response to oxytocin and adverse effects $3 \mathrm{~min}$ after the initial bolus administration may have also been confounded by parturients accepting the rescue dose of oxytocin. However, we could not allow an inadequate UT and bleeding to continue untreated, so we adopted the "Rule of Three" algorithm. ${ }^{33}$ Second, although senior attending obstetricians assessed the uterus, these assessments were subjective. However, objective evaluation methods are lacking, and our approach is similar to that of other scholars. ${ }^{21,26,31,32}$ Third, our study was designed to compare the $\mathrm{ED}_{50}$ of a prophylactic oxytocin bolus during $\mathrm{CD}$

Table 2 Secondary Outcomes and Adverse Events

\begin{tabular}{|c|c|c|c|}
\hline & $\begin{array}{l}\text { Young } \\
(n=28)\end{array}$ & $\begin{array}{l}\text { Old } \\
(n=25)\end{array}$ & $P$ \\
\hline Estimated blood loss (mL) & $289.3 \pm 104.6$ & $401.2 \pm 204.5$ & 0.01 \\
\hline Postoperative hemoglobin $(\mathrm{g} / \mathrm{L})$ & $105.8 \pm 12.5$ & $98.3 \pm 9.0$ & 0.59 \\
\hline Total volume of crystalloid (i.v.) (mL) & $960.0 \pm 154.6$ & $1060.0 \pm 390.2$ & 0.22 \\
\hline Total oxytocin dose (IU) & $4.1 \pm 2.1$ & $5.9 \pm 2.9$ & 0.01 \\
\hline Delivery time of placenta (s) & $129.3 \pm 50.0$ & $131.0 \pm 47.9$ & 0.90 \\
\hline \multicolumn{4}{|l|}{ Lowest blood pressure $(\mathrm{mmHg})$} \\
\hline Systolic & $98.3 \pm 9.0$ & $99.4 \pm 13.2$ & 0.73 \\
\hline Diastolic & $46.5 \pm 8.3$ & $48.5 \pm 11.1$ & 0.45 \\
\hline Mean & $69.3 \pm 8.7$ & $70.0 \pm 10.5$ & 0.78 \\
\hline Supplemental uterotonic agents & $3(10.7)$ & $8(32.0)$ & 0.06 \\
\hline \multicolumn{4}{|l|}{ Adverse effects } \\
\hline Overall & $6(21.4)$ & $17(68.0)$ & 0.001 \\
\hline Headache & $0(0)$ & $3(12.0)$ & 0.20 \\
\hline Nausea and/or vomiting & I (3.6) & $4(16.0)$ & 0.28 \\
\hline Chest pain & $4(14.3)$ & $8(32.0)$ & 0.12 \\
\hline Flushing & I (3.6) & $2(8.0)$ & 0.92 \\
\hline Hypotension & $3(10.7)$ & $5(20.0)$ & 0.45 \\
\hline Tachycardia & $0(0)$ & $0(0)$ & 1 \\
\hline
\end{tabular}

Note: Data are the mean \pm standard deviation or number (\%). 
but, in clinical practice, many anesthetists and obstetricians may prefer to administer oxytocin at a dose closer to the $\mathrm{ED}_{90}$ or $\mathrm{ED}_{95}$ to obtain an adequate UT to prevent postpartum hemorrhage. Further studies investigating the effect of oxytocin on higher points on the dose-response curve may be of interest. Fourth, although the attending obstetricians were blinded to the oxytocin dose administered, they were aware of the age difference between the two groups. Hence, they may have had a different threshold for an adequate UT in either group.

\section{Conclusions}

The ED50 of the oxytocin bolus administered during the third stage of labor was significantly higher in older parturients compared with that in younger parturients undergoing elective $\mathrm{CD}$. These results are consistent with reports of a greater oxytocin requirement in older parturients. $^{9,22}$ Advanced maternal age should be considered a factor for the prevention of uterine tony in elective CD. We suggest that guidelines for oxytocin administration should differentiate between young parturients and old parturients (age $\geq 35$ years).

\section{Data Sharing Statement}

Data analyzed during this study are available from the corresponding author upon reasonable request.

\section{Acknowledgments}

The authors thank the attending obstetricians and all staff in the Department of Anesthesia and the Operating Theatre of the Jia Xing University Affiliated Women and Children Hospital for their help in this study.

\section{Funding}

The study was supported by a research grant from the National Natural Science Foundation of China (81271237).

\section{Disclosure}

The authors report no conflicts of interest in this work.

\section{References}

1. Office for National Statistics for Births in England and Wales 2018 2018. Births in England and wales: 2018. Available from: https://www. ons.gov.uk/peoplepopulationandcommunity/birthsdeathsandmarriages/ livebirths/bulletins/birthsummarytablesenglandandwales/2018\#mainpoints. Accessed November 11, 2020.

2. Matthews TJ, Hamilton BE. First births to older women continue to rise. NCHS Data Brief. 2014;152:1-8.
3. Gong W, Xu DR, Caine ED. Challenges arising from China's twochild policy. Lancet. 2016;387(10025):1274. doi:10.1016/S01406736(16)30020-4

4. Ecker JL, Chen KT, Cohen AP, Riley LE, Lieberman ES. Increased risk of cesarean delivery with advancing maternal age: indications and associated factors in nulliparous women. Am J Obstet Gynecol. 2001;185(4):883-887. doi:10.1067/mob.2001.117364

5. Montan S. Increased risk in the elderly parturient. Curr Opin Obstet Gynecol. 2007;19(2):110-112. doi:10.1097/ GCO.0b013e3280825603

6. Lao TT, Sahota DS, Cheng YK, Law LW, Leung TY. Advanced maternal age and postpartum hemorrhage - risk factor or red herring? J Matern Fetal Neonatal Med. 2014;27(3):243-246. doi:10.3109/ 14767058.2013.807240

7. Smith GC, Cordeaux Y, White IR, et al. The effect of delaying childbirth on primary cesarean section rates. PLoS Med. 2008;5(7): e144. doi:10.1371/journal.pmed.0050144

8. Arrowsmith S, Robinson H, Noble K, Wray S. What do we know about what happens to myometrial function as women age? $J$ Muscle Res Cell Motil. 2012;33(3-4):209-217. doi:10.1007/s10974-0129300-2

9. Greenberg MB, Cheng YW, Sullivan M, Norton ME, Hopkins LM, Caughey AB. Does length of labor vary by maternal age? Am J Obstet Gynecol. 2007;197(4):428.e1-7. doi:10.1016/j. ajog.2007.06.058

10. Heesen M, Carvalho B, Carvalho J, et al. International consensus statement on the use of uterotonic agents during caesarean section. Anaesthesia. 2019;74(10):1305-1319. doi:10.1111/anae.14757

11. Pace NL, Stylianou MP. Advances in and limitations of up-and-down methodology: a précis of clinical use, study design, and dose estimation in anesthesia research. Anesthesiology. 2007;107(1):144-152. doi:10.1097/01.anes.0000267514.42592.2a

12. Wei CN, Zhang YF, Xia F, Wang LZ, Zhou QH. Abdominal girth, vertebral column length and spread of intrathecal hyperbaric bupivacaine in the term parturient. Int J Obstet Anesth. 2017;31:63-67. doi:10.1016/j.ijoa.2017.02.002

13. Park HJ, Lee JR, Kim CS, Kim SD, Kim HS. Remifentanil halves the EC50 of propofol for successful insertion of the laryngeal mask airway and laryngeal tube in pediatric patients. Anesth Analg. 2007;105(1):57-61. doi:10.1213/01.ane.0000266447.23037.e4

14. Lee SY, Jeong YY, Lee BH, Kim JE. Sex-related differences in effect-site concentration of remifentanil for preventing anesthetic emergence cough in elderly patients. Clin Interv Aging. 2018;5 (13):81-89. doi:10.2147/CIA.S151476

15. Xu B, Li Z, Zhou D, Li L, Li P, Huang H. The influence of age on sensitivity to dexmedetomidine sedation during spinal anesthesia in lower limb orthopedic surgery. Anesth Analg. 2017;125(6):19071910. doi:10.1213/ANE.0000000000002531

16. Dixon WJ. Staircase bioassay: the up-and-down method. Neurosci Biobehav Rev. 1991;15(1):47-50. doi:10.1016/S0149-7634(05) 80090-9

17. Paul M, Fisher DM. Are estimates of MAC reliable? Anesthesiology. 2001;95(6):1362-1370. doi:10.1097/00000542-200112000-00014

18. Dyer RA, van Dyk D, Dresner A. The use of uterotonic drugs during caesarean section. Int $J$ Obstet Anesth. 2010;19(3):313-319. doi:10.1016/j.ijoa.2010.04.011

19. Weale N, Laxton C. Prophylactic use of oxytocin at caesarean section: where are the guidelines? Anaesthesia. 2013;68(10):1006-1009.

20. Kjaer BN, Krøigaard M, Garvey LH. Oxytocin use during Caesarean sections in Denmark - are we getting the dose right? Acta Anaesthesiol Scand. 2016;60(1):18-25. doi:10.1111/aas.12603

21. Duffield A, McKenzie C, Carvalho B, et al. Effect of a high-rate versus a low-rate oxytocin infusion for maintaining uterine contractility during elective cesarean delivery: a prospective randomized clinical trial. Anesth Analg. 2017;124(3):857-862. doi:10.1213/ ANE.0000000000001658 
22. Bobrowski RA, Bottoms SF. Underappreciated risks of the elderly multipara. Am J Obstet Gynecol. 1995;172(6):1764-1767. doi:10.1016/0002-9378(95)91409-9

23. Main DM, Main EK, Moore DH. The relationship between maternal age and uterine dysfunction: a continuous effect throughout reproductive life. Am J Obstet Gynecol. 2000;182(6):1312-1320. doi:10.1067/mob.2000.106249

24. Patel R, Moffatt JD, Mourmoura E, et al. Effect of reproductive ageing on pregnant mouse uterus and cervix. J Physiol. 2017;595 (6):2065-2084. doi:10.1113/JP273350

25. Thomas JS, Koh SH, Cooper GM. Haemodynamic effects of oxytocin given as i.v. bolus or infusion on women undergoing Caesarean section. Br J Anaesth. 2007;98(1):116-119. doi:10.1093/bja/ael302

26. Terblanche N, Otahal P, Messmer A, et al. An observational cohort study of 3 units versus 5 units slow intravenous bolus oxytocin in women undergoing elective caesarean delivery. $J$ Physiol Pharmacol. 2017;68(4):547-553.

27. Jonsson M, Hanson U, Lidell C, Nordén-Lindeberg S. ST depression at caesarean section and the relation to oxytocin dose. A randomised controlled trial. BJOG. 2010;117(1):76-83. doi:10.1111/j.14710528.2009.02356.x

28. Butwick AJ, Coleman L, Cohen SE, Riley ET, Carvalho B. Minimum effective bolus dose of oxytocin during elective Caesarean delivery. Br J Anaesth. 2010;104(3):338-343. doi:10.1093/bja/aeq004
29. Sheen JJ, Wright JD, Goffman D, et al. Maternal age and risk for adverse outcomes. Am J Obstet Gynecol. 2018;219(4):390.e1-390. e15. doi:10.1016/j.ajog.2018.08.034

30. Durmaz A, Komurcu N. Relationship between maternal characteristics and postpartum hemorrhage: a meta-analysis study. J Nurs Res. 2018;26(5):362-372. doi:10.1097/jnr.0000000000000245

31. Lavoie A, McCarthy RJ, Wong CA. The ED90 of prophylactic oxytocin infusion after delivery of the placenta during cesarean delivery in laboring compared with nonlaboring women: an updown sequential allocation dose-response study. Anesth Analg. 2015;121(1):159-164. doi:10.1213/ANE.0000000000000781

32. Qian XW, Drzymalski DM, Lv CC, Guo FH, Wang LY, Chen XZ. The ED50 and ED95 of oxytocin infusion rate for maintaining uterine tone during elective caesarean delivery: a dose-finding study. $B M C$ Pregnancy Childbirth. 2020;20(1):6. doi:10.1186/s12884-019-2692-x

33. Kovacheva VP, Soens MA, Tsen LC. A randomized, double-blinded trial of a "rule of threes" algorithm versus continuous infusion of oxytocin during elective cesarean delivery. Anesthesiology. 2015;123 (1):92-100. doi:10.1097/ALN.0000000000000682

\section{Publish your work in this journal}

Drug Design, Development and Therapy is an international, peerreviewed open-access journal that spans the spectrum of drug design and development through to clinical applications. Clinical outcomes, patient safety, and programs for the development and effective, safe, and sustained use of medicines are a feature of the journal, which has also been accepted for indexing on PubMed Central. The manuscript management system is completely online and includes a very quick and fair peer-review system, which is all easy to use. Visit http://www. dovepress.com/testimonials.php to read real quotes from published authors. 